\title{
An exploration of mental health literacy in relation to depression in secondary school pupils
}

\author{
Ericka Doyle \\ School of Psychology, University College Dublin \\ Belfield Court, Dublin 4, Ireland \\ Email: rickydoyle82@gmail.com \\ Shaunagh O'Sullivan \\ School of Psychology, University College Dublin \\ Belfield Court, Dublin 4, Ireland \\ Email: shaunagh.o-sullivan@ucdconnect.ie \\ Finiki A. Nearchou (Corresponding author) \\ School of Psychology, University College Dublin \\ Belfield Court, Dublin 4, Ireland \\ Tel: +353017168356 E-mail: niki.nearchou@ucd.ie \\ Eilis Hennessy \\ School of Psychology, University College Dublin \\ Belfield Court, Dublin 4, Ireland \\ Tel: +353017168362 E-mail: eilis.hennessy@ucd.ie
}

Received: November 9, 2016

doi:10.5296/jet.v4i2.10287
Accepted: January 4, 2017

Published: July 28, 2017

URL: http://dx.doi.org/10.5296/jet.v4i2.10287

\begin{abstract}
Mental Health Literacy (MHL) refers to knowledge and beliefs about mental health problems. Although mostly studied in adult samples, it has been associated with help-seeking intentions and health service use in adolescents. The aim of the present study was to explore depression MHL and its association with help seeking intentions in a sample of adolescent participants ( $n=235,135$ males) from the final three years of secondary school (mean $=16.6$ years, $S D$ $=.65$ ) in Ireland. Knowledge of depression and help-seeking intentions were measured using vignettes and self-report instruments. Findings show that the majority of adolescents recognised that a combination of depression symptoms constituted a serious mental health problem. However, they demonstrated very low MHL levels on specific symptoms such as somatic pains. The finding of restricted knowledge of depression symptoms, indicates a need for targeted interventions to improve MHL, and specifically of symptoms of depression.
\end{abstract}

Keywords: mental health literacy; adolescence; depression; youth mental health; help-seeking 


\section{Introduction}

A recent review of national rates of mental health problems among adolescents around the world put the median prevalence rate of major depressive disorder (MDD) at 4\% (ranging from $<1 \%$ to $17 \%$ ), with lifetime prevalence rates from $23 \%$ to $43 \%$ (Merikangas et al., 2009). Prevalence rates of sub-threshold depressive disorders and minor depression are typically higher. For example, research with a representative sample of adolescents in the USA estimated a lifetime prevalence rate of $14 \%$ for mood disorders (Merikangas et al., 2010). An Irish population-based study in adolescents aged 11-13 years detected high levels of mental disorder symptomatology, with MDD featuring among the leading current and lifetime disorders (Coughlan et al., 2014). Notably, a similar but earlier study demonstrated that Irish youth faced significant mental health issues, with $10 \%$ being at risk for affective disorders (Lynch, Mills, Daly, \& Fitzpatrick, 2006). Depression has been extensively associated with suicide attempts and ideation (De Leo \& Too, 2014) and suicide is a leading cause of death in young people (Avenevoli et al., 2015). Despite the publication of guidelines on the promotion of mental well-being in schools in Ireland (Department of Education \& Skills, 2013) the evidence suggests that renewed efforts are needed to ensure that young people can identify the symptoms of mental health problems that are common during adolescence and know that it is important to seek help should it be needed.

\subsection{Mental Health Literacy}

An important element of any strategy to address mental health difficulties is an understanding of Mental Health Literacy (MHL) because it has been identified as a factor associated with positive mental health, reduced stigma and enhanced help-seeking skills. MHL is defined as 'knowledge and beliefs about mental disorders which aid their recognition, management or prevention' (Jorm et al., 1997, p. 182). Mental health literacy has multiple components that encompass: (1) the ability to recognise potential symptoms of mental disorders; (2) beliefs about risk factors and causes of mental illnesses; (3) the knowledge of how to seek appropriate professional help and available self-help interventions; and (4) attitudes that facilitate and enhance the help-seeking procedure.

MHL has been particularly linked to depressive disorders. The majority of studies that documented levels of MHL and further explored the pathways that relate the construct with psychological well-being were mainly conducted in adults. As such, the available empirical evidence on adolescents' MHL levels is relatively limited, while our knowledge on the established links of MHL to mental disorders is even more confined. Higher scores on measures of MHL have been associated with more effective help-seeking skills and efficient treatment preferences in youth, which in turn contributes to maintaining a better mental health status (Wright, Jorm, Harris, \& McGorry, 2007). In general, poor mental health literacy has been related to lower rates of help-seeking and service use (Gulliver, Griffiths \& Christensen, 2010). Furthermore, low levels of MHL have been found to severely diminish the capacity of help-seeking in individuals already suffering from a mental disorder (Rickwood, White, \& Eckersley, 2007; Vanheusden et al., 2009), thus putting them at increased risk of remaining untreated. Findings from recent studies suggest that MHL plays a 
vital role in adolescents' mental health status because it is linked to specific conditions such as depression (Lam, 2014).

\subsubsection{Mental Health Literacy \& Theory of Planned Behaviour}

The Theory of Planned Behaviour (TPB) is a theoretical model developed to explain the underlying mechanisms that define whether the individual will engage or not with a specific health behaviour (Ajzen, 1991). TPB has been extensively supported with empirical evidence regarding its applicability on various health/mental health issues (Ogden, 2012). According to this model, attitudes directly affect the extent to which one intends to actually engage with a health behaviour. Drawing from the assertion that MHL has an influential role on mental health status (Lam, 2014) and acknowledging that help-seeking is the targeted health behaviour that will eventually lead to effective treatment, the present paper is guided by the theoretical perspectives of TPB. As previously discussed, higher levels of MHL are associated with certain beliefs and more positive attitudes towards mental health problems. Hence, the help-seeking capacity is enhanced, appropriate treatment is received, which in turn contributes to better well-being.

\subsection{Gender Differences}

Females are significantly more likely to be diagnosed with depression than males (Sen, 2004). However, females are also more likely to seek help when experiencing a mental health difficulty (Boldero \& Fallon, 1995). This may be related to previous findings suggesting that young females possess higher levels of mental health literacy than young males (Burns \& Rapee, 2006; Cotton et al., 2006; Williams \& Pow, 2007). The limited number of studies that examined gender differences in Irish youth documented differences between boys and girls on their knowledge of mental disorders. For example evidence from a nationwide survey in Irish adolescents suggested that females reported significantly higher scores on a measure of MHL compared to their male counterparts (Chambers \& Murphy, 2011). Another study (Byrne, Swords, \& Nixon, 2015), confirmed the pattern that females tend to report higher levels of MHL than males as well as a significantly greater ability to identify depression symptoms. The relatively high rates of depression and suicide among Irish youth compared to their counterparts from other European countries (National Educational Psychological Service, 2013) require further examination of the patterns of recorded mental health literacy levels accounted for by gender, in order to expand the existing knowledge on this field and act as a starting point for developing more tailored interventions.

\subsection{The Study Purposes}

It has been suggested that if all cases of depression were treated successfully in early adolescence, the risk of major depression in later adolescence would be reduced by approximately $10 \%$ (Belfer \& Saxena, 2006). The literature suggests that the rates of youth receiving treatment remain low, in part because the majority of those experiencing a mental disorder will not seek professional treatment (Merikangas et al., 2010; Reavley, Cvetkovski, Jorm, \& Lubman, 2010). So far research evidence on MHL levels on depression in Irish adolescents is limited, while the few available studies indicate that MHL levels are low. 
Therefore, the present study seeks to fill this gap by investigating the ability of adolescents to identify manifestations of major depressive disorder as well as their help-seeking attitudes towards the disorder. Furthermore, considering the limited empirical evidence on gender differences in mental health literacy in Irish youth, another aim of the current investigation is to enrich the existing MHL literature by exploring potential discrepancies on the identification of depression manifestations between male and female adolescent pupils.

\section{Method}

\subsection{Participants and Data Collection}

The participants $(n=235)$ were adolescent male $(57.6 \%)$ and female pupils, attending $4^{\text {th }}$ $(55.3 \%), 5^{\text {th }}(40.4 \%)$ and $6^{\text {th }}$ year $(4.3 \%)$ at secondary schools (mean age $=16.6$ years, $S D$ $=.652)$. These were single sex girls' schools (34.9\%), single sex boys' schools $(46.8 \%)$ and co-educational (mixed) schools (18.3\%) located in Ireland in the greater Dublin area and both DEIS and non-DEIS schools were included. DEIS stands for Delivering Equality of Opportunity in School, which is an action plan for educational inclusion to address educational disadvantage in schools. Data were collected by administering a self report anonymous questionnaire to record demographic information and measure knowledge of depression manifestations and help-seeking intentions.

\subsection{Measures}

The most widely employed tool to assess MHL levels regarding depression symptoms is a series of questions following a vignette. This method has been widely employed for investigating adolescents' personal interpretations on sensitive issues such as mental illness (Burns \& Rapee, 2006; Byrne et al., 2015; Dolphin \& Hennessy, 2014; Leighton, 2010). These vignettes are "short stories about hypothetical characters in specified circumstances, to whose situation the interviewee is invited to respond" (Finch, 1987, p.105). Vignettes, viewed as a projective technique, enable participants to express themselves by emotionally distancing them from their own experiences, while at the same time elicit responses that reflect participants' personal perceptions, ideas and thoughts on specific topics (de Macedo, Khanlou, \& Luis, 2015; Leighton, 2010). Furthermore some research evidence suggest that using vignettes may counterbalance the effect of social desirability because respondents are asked indirectly to express their views, perceptions and thoughts (Ganong \& Coleman, 2006). In order to assess MHL in relation to depression vignettes were presented to all participants. There were two versions of the vignettes, one describing the story of a female (Vanessa) and the other of a male (Killian), young fictional character suffering from depressive symptoms that met DSM-5 criteria for depression diagnosis: negative feelings, changes in thoughts (negative or/and slower thoughts), low energy, loss of interest in daily activities and friends, sleep disturbances, loss of interest in life and living, low value of self (see Appendix 1 and 2). The vignette depicting the female character was presented to female participants and the male character to male participants. 


\subsection{Procedure}

After obtaining approval from the local ethics committee of University College Dublin, 30 secondary schools were sent details about the study's aims, objectives and methods via email and post. Schools who agreed to participate $(n=10)$ were provided with information sheets and consent forms to distribute to students. Participation was voluntary and signed parental consent forms were required for participants under the age of 18. Verbal assent was sought from participants on the day of testing and all students were briefed prior to completing the questionnaires. Pupils completed the self-report measures described above within normal class hours.

\subsection{Data Analysis}

Open-ended items were analysed using key words in participants' answers to determine whether or not they had identified that the vignette character might be experiencing a serious problem and/or the presence of specific depression-related symptoms. Responses to the question "Can you identify anything that might suggest that there may be a problem" that contained words/phrases quoting sections of the vignettes or related to syptoms were coded as a positive identification of the symptom For example "feeling tired" was coded as identification of low energy/tirediness; "doesn't sleep well" was coded as identification of sleep disturbances. Coding qualitative items was followed by performing chi-square tests of goodness-of-fit to examine difference in participants' answers and chi-square tests of independence to examine gender related differences in participants' answers. All the statistical analyses were conducted using SPSS software (version 21).

\section{Results}

Levels of MHL were examined by recording the participants' responses on four categorical items that followed the vignettes. As illustrated in Table 1 the large proportion of adolescents acknowledged that the fictional vignette character (either male or female) was experiencing a serious condition which was not typical of their age stage. Chi square tests $\left(\chi^{2}\right)$ of goodness-of-fit were performed to determine whether the proportion of respondents indicating that the condition is serious is statistically different from those indicating the the condition is not serious. The results showed that the number of pupils that recognized the condition as serious $(n=209)$ and not typical $(n=171)$ reached significance (see Table 1$)$ when compared to the number of their counterparts that did not confirm the above ( $n=26$ and $n=64$ respectively).

\subsection{Help - seeking intentions}

Similarly, chi square tests $\left(\chi^{2}\right)$ were conducted to examine differences in participants' responses regarding: a) their decision to seek help if they were the fictional character and $b$ ) the extent to which they would feel confident to help themselves if they were the adolescent presented at the vignette. Table 1 shows that the proportion of pupils who indicated that they would seek help if they were the vignette character, was significantly higher $(n=184)$ than the proportion of participants who indicated that they would not $(n=51)$. When asked whether there is anything they could do to help themselves if they were the fictional character, 
the significant majority of the participants $(n=205)$ answered yes.

In order to examine the relationship between the ability to perceive the extent to which a condition is serious and the intention to seek help chi square tests $\left(\chi^{2}\right)$ of independence were performed. The results showed that a significantly larger proportion of participants $(83 \%)$ who considered that the fictional character was experiencing serious a serious problem indicated that they would seek help if they were the character $\left(\chi^{2}=19.9, p<.001\right)$. Similarly, a large proportion $(62 \%)$ of the adolescents who perceived the feelings and behaviours of the characters as not typical of a teenager indicated that they would seek help if they were the character $\left(\chi^{2}=12.1, p<.001\right)$.

Table 1. Mental health literacy levels and help - seeking intentions per gender and overall

\begin{tabular}{|c|c|c|c|c|c|c|c|c|}
\hline & \multicolumn{2}{|c|}{$\begin{array}{c}{ }^{1} \text { Typical teenager } \\
\text { feelings }\end{array}$} & \multicolumn{2}{|c|}{$\begin{array}{l}{ }^{2} \text { Experiencing } \\
\text { serious problem }\end{array}$} & \multicolumn{2}{|c|}{${ }^{3}$ Would seek help } & \multicolumn{2}{|c|}{${ }^{4}$ Help themselves } \\
\hline & No & Yes & No & Yes & No & Yes & No & Yes \\
\hline Girls & $\begin{array}{l}82.7 \% \\
(n=81)\end{array}$ & $\begin{array}{l}17.3 \% \\
(n=17)\end{array}$ & $\begin{array}{l}5.1 \% \\
(n=5)\end{array}$ & $\begin{array}{l}94.9 \% \\
(n=94)\end{array}$ & $\begin{array}{l}21.2 \% \\
(n=21)\end{array}$ & $\begin{array}{l}78.8 \% \\
(n=78)\end{array}$ & $\begin{array}{l}8.3 \% \\
(n=8)\end{array}$ & $\begin{array}{l}91.7 \% \\
(n=88)\end{array}$ \\
\hline Boys & $\begin{array}{l}66.2 \% \\
(\mathrm{n}=90)\end{array}$ & $\begin{array}{l}33.8 \% \\
(n=46)\end{array}$ & $\begin{array}{l}15.4 \% \\
(n=21)\end{array}$ & $\begin{array}{c}84.6 \% \\
(n=115)\end{array}$ & $\begin{array}{l}22.1 \% \\
(n=30)\end{array}$ & $\begin{array}{c}79.9 \% \\
(n=106)\end{array}$ & $\begin{array}{l}13.3 \% \\
(n=18)\end{array}$ & $\begin{array}{l}86.7 \% \\
(n=117)\end{array}$ \\
\hline $\begin{array}{c}\text { Chi } \\
\text { square }\end{array}$ & \multicolumn{2}{|c|}{$\begin{aligned} \chi^{2} & =7.044, \quad \mathrm{p} \\
& =.008^{* *}\end{aligned}$} & \multicolumn{2}{|c|}{$\begin{aligned} \chi^{2} & =5.27, \mathrm{p} \\
& =.022^{*}\end{aligned}$} & \multicolumn{2}{|c|}{$\chi^{2}=.024, p=.876$} & \multicolumn{2}{|c|}{$\chi^{2}=.948, p=.330$} \\
\hline Total & $\begin{array}{l}72.8 \% \\
(n=64)\end{array}$ & $\begin{array}{c}27.2 \% \\
(n=171)\end{array}$ & $\begin{array}{l}11.1 \% \\
(n=26)\end{array}$ & $\begin{array}{c}88.9 \% \\
(n=209)\end{array}$ & $\begin{array}{l}21.7 \% \\
(n=51)\end{array}$ & $\begin{array}{c}78.3 \% \\
(n=184)\end{array}$ & $\begin{array}{c}11.3 \% \\
(n=205)\end{array}$ & $\begin{array}{l}88.7 \% \\
(n=30)\end{array}$ \\
\hline $\begin{array}{l}\text { Chi } \\
\text { square }\end{array}$ & \multicolumn{2}{|c|}{$\begin{aligned} \chi^{2} & =48.7, \quad p \\
& <.001^{* *}\end{aligned}$} & $\begin{array}{l}\chi^{2}= \\
<.001^{*}\end{array}$ & $142, \quad \mathrm{p}$ & \multicolumn{2}{|c|}{$\begin{array}{c}\chi^{2}=75.2, \mathrm{p} \\
<.001^{* *}\end{array}$} & \multicolumn{2}{|c|}{$\begin{aligned} \chi^{2} & =138.7, p \\
& <.001^{* *}\end{aligned}$} \\
\hline
\end{tabular}

Note: $* p<.05, * * p<.01, * * * p<.001$

1 Do you think Killian's /Vanessa's feelings are typical of a teenager? 2 Do you think Killian / Vanessa may be experiencing a more serious problem? 3 If you were Killian / Vanessa would you seek help? 4 Is there anything Killian / Vanessa could do to help himself / herself?

\subsection{Gender Differences in Help Seeking Intentions and Mental Health Literacy}

In order to examine whether boys and girls differed in their MHL level in relation to depression and their views about help-seeking, chi square tests of independence $\left(\chi^{2}\right)$ were performed. Table 1 presents the percentages of participants' responses to the four items that explored their MHL levels accounted for by gender and includes the outcomes of the chi square tests. The analyses on gender differences showed that girls were significantly more likely than boys to state that the condition presented in the vignette was serious and not typical of adolescent behaviour. However, participants did not differ in their answers regarding their help-seeking intentions (see Table 1). 


\subsection{Identification of Depression Symptoms}

The vignette used in this study described a character displaying eight identifiable symptoms of depression. Our findings indicate that although the majority of participants identified that the character had a serious mental health problem, only a minority were able to correctly identify the individual symptoms that were indicative of this problem. Chi square tests were performed to examine the differences between those that did and did not identify individual depression symptoms. As shown in Table 2, the participants who did not correctly identify each of the 7 symptoms of depression embedded in the vignette significantly outnumbered those that did: negative feelings $\left(\chi^{2}=49.4, p<.001\right)$; loss of interest in daily activities $\left(\chi^{2}=94.4, p<.001\right)$; loss of interest in life $\left(\chi^{2}=10.2, p=.001\right)$; low energy/tirediness $\left(\chi^{2}=213.1, p<.001\right)$; sleep disturbances $\left(\chi^{2}=171.9, p<.001\right)$; changes in thoughts $\left(\chi^{2}=231.1, p<.001\right)$ and low value of self $\left(\chi^{2}=215.4, p<.001\right)$.

Table 2. Depression symptom identification rates per gender and overall

\begin{tabular}{|c|c|c|c|c|c|c|c|}
\hline & Feelings & $\begin{array}{l}\text { Loss of } \\
\text { energy }\end{array}$ & Sleep & $\begin{array}{l}\text { Changes } \\
\text { in } \\
\text { thoughts }\end{array}$ & $\begin{array}{l}\text { Value } \\
\text { for self }\end{array}$ & $\begin{array}{l}\text { Loss of interest } \\
\text { - daily } \\
\text { activities }\end{array}$ & $\begin{array}{l}\text { Loss of } \\
\text { interest in } \\
\text { living }\end{array}$ \\
\hline $\begin{array}{l}\text { Identified- } \\
\text { Total (\%) }\end{array}$ & $\begin{array}{c}28.5 \\
(n=67)\end{array}$ & $\begin{array}{c}1.7 \\
(n=4)\end{array}$ & $\begin{array}{c}7.2 \\
(n=17) \\
\end{array}$ & $\begin{array}{c}0.4 \\
(\mathrm{n}=1)\end{array}$ & $\begin{array}{c}2.1 \\
(\mathrm{n}=5)\end{array}$ & $\begin{array}{c}18.3 \\
(n=43)\end{array}$ & $\begin{array}{c}39.6 \\
(n=93)\end{array}$ \\
\hline Boys & $\begin{array}{c}24.3 \\
(n=33)\end{array}$ & $\begin{array}{c}1.5 \\
(n=2)\end{array}$ & $\begin{array}{c}4.4 \\
(n=6)\end{array}$ & $\begin{array}{l}0.00 \\
(n=0)\end{array}$ & $\begin{array}{c}2.2 \\
(n=3)\end{array}$ & $\begin{array}{c}11.8 \\
(n=16)\end{array}$ & $\begin{array}{c}39.7 \\
(n=54)\end{array}$ \\
\hline Girls & $\begin{array}{c}34.3 \\
(n=34)\end{array}$ & $\begin{array}{c}2.0 \\
(n=2)\end{array}$ & $\begin{array}{c}11.1 \\
(n=11)\end{array}$ & $\begin{array}{c}1.0 \\
(\mathrm{n}=1)\end{array}$ & $\begin{array}{c}2.0 \\
(n=2)\end{array}$ & $\begin{array}{c}27.3 \\
(n=27)\end{array}$ & $\begin{array}{c}39.4 \\
(n=39)\end{array}$ \\
\hline $\begin{array}{l}\text { Not } \\
\text { identified- } \\
\text { Total (\%) }\end{array}$ & $\begin{array}{c}71.5 \\
(n=168)\end{array}$ & $\begin{array}{c}98.3 \\
(n=231)\end{array}$ & $\begin{array}{c}92.8 \\
(\mathrm{n}=218)\end{array}$ & $\begin{array}{c}99.6 \\
(n=234)\end{array}$ & $\begin{array}{c}97.9 \\
(n=230)\end{array}$ & $\begin{array}{c}81.7 \\
(n=192)\end{array}$ & $\begin{array}{c}60.4 \\
(n=142)\end{array}$ \\
\hline Boys & $\begin{array}{c}75.7 \\
(n=103)\end{array}$ & $\begin{array}{c}98.5 \\
(n=134)\end{array}$ & $\begin{array}{c}95.6 \\
(n=130)\end{array}$ & $\begin{array}{c}100.0 \\
(n=136)\end{array}$ & $\begin{array}{c}97.8 \\
(n=133)\end{array}$ & $\begin{array}{c}88.2 \\
(n=120)\end{array}$ & $\begin{array}{c}60.3 \\
(n=82)\end{array}$ \\
\hline Girls & $\begin{array}{c}65.7 \\
(n=65)\end{array}$ & $\begin{array}{c}98 \\
(n=97)\end{array}$ & $\begin{array}{c}88.9 \\
(n=88)\end{array}$ & $\begin{array}{c}99.0 \\
(n=98)\end{array}$ & $\begin{array}{c}98.0 \\
(n=97)\end{array}$ & $\begin{array}{c}72.7 \\
(n=72)\end{array}$ & $\begin{array}{c}60.6 \\
(n=60)\end{array}$ \\
\hline
\end{tabular}

\section{Discussion}

The present study sought to document MHL levels associated with depression and help-seeking intentions among youth in Ireland. The majority of adolescents that participated in this study recognised the existence of a serious condition and reported the behaviours presented in the vignette scenarios as not typical of a teenager. Aligned with the existing literature this finding further consolidates previous evidence that teenagers can identify the presence of a condition that induces emotional distress and operates outside the normal boundaries of functioning (e.g. Leighton, 2010). Leighton (2009) argued that primary focus should be placed on the ability to recognise the occurrence of a mental issue and on the intention to seek help and not only on the correct identification/labeling of the problem per se. 
As previously discussed, the theoretical guidelines of TPB that provide explanations on pathways associated with inducing a health behaviour, can be applied to interpret the outcomes of the present study. Correctly identifying the existence of a problem and acknowledging its magnitude in terms of seriousness may enhance help-seeking intentions and result in engaging with the actual health behaviour (Ogden, 2012). The current investigation provided evidence that most of the adolescents who perceived the condition of the fictional character as problematic and serious expressed an intention to seek help. Hence, it was demonstrated that pupils who anticipated the existence of a mental health problem that needed to be addressed indicated a greater willingness to engage in the actual health behaviour (ie. seek help), which in turn might result in improving their mental health status.

Overall, the results indicated very low MHL levels on specific symptoms of depression. Respondents who identified specific symptoms of depression were significantly outnumbered by those that did not recognise the symptoms embedded in the hypothetical scenarios, thus supporting empirical findings from other studies in Irish youth. For example, Byrne and colleagues (2015) found that only a significantly small proportion of adolescents were able to label depressive symptoms when presented with different hypothetical scenarios. Considering the relatively high rates of depression and suicide among Irish adolescents and the association of MHL with the intention to seek help, the aforementioned finding generates great concern. Loss of interest in life and living was the most frequently endorsed manifestation of depression followed by experiencing negative feelings and loss of interest in friends and pleasant activities. Interestingly, other symptoms of depression like changes in thoughts, low self-esteem and sleep disturbances were listed by very few pupils. Empirical evidence from similar studies conducted in other national adolescent cohorts suggest different patterns of recognition on depression symptoms. Although Burns and Rapee (2006) also showed that loss of interest in activities was the most frequently identified indicator of depression by Australian adolescents, sleep disturbances and diminished ability to think were also commonly identified (Burns \& Rapee, 2006). Moreover, the rates of symptom labeling were higher than those found in the current study. It can be suggested that MHL levels on manifestations of depression tend to vary across cultures and are subject to unique national contexts, including for example, educational curricula and/or public health campaigns. The present study extended the knowledge on the specific features of depression that are recognisable by Irish school pupils. Consequently, this poses a challenge that policy makers should address in designing interventions for promoting MHL in Irish secondary education settings.

Examination of gender differences yielded mixed results. Girls were more likely to perceive that the condition presented in the vignette was serious and not common for young people, however there were no gender differences in help-seeking intentions. This finding is partially consistent with evidence derived from similar studies with youth in both Ireland and other countries. There is general consensus among researchers that girls tend to report higher levels of MHL on depression and demonstrate more positive attitudes towards help-seeking than boys. However, outcomes of the present study suggest that there may be a different pattern in help seeking attitudes among Irish youth that warrants further examination contradicting 
previous evidence that boys prefer to cope with depression alone (Jorm et al., 2006). Moreover, girls possess better knowledge of specific depression related behavioural and emotional features (Byrne et al., 2015), which has been attributed to their greater social exposure to depression especially during late adolescence (Burns \& Rapee, 2006). The results of the present study imply that girls have better knowledge solely on one specific manifestation of depression, that is losing interest in friends and previously enjoyed activities. Given that depression remains a major public health problem and improving knowledge results in better help seeking strategies, outcomes of the present study shed further light into the existing patterns of MHL among Irish youth.

\subsection{Limitations}

The present study significantly adds to the existing literature on MHL among youth and their help-seeking intentions. However, there are some limitations that need to be taken into consideration. Firstly, the present study, as the majority of mental health literacy research, employed vignettes for assessing knowledge of depression and help-seeking intentions. Despite the commonly accepted usefulness of the aforementioned tool, the applicability of this type of data into real life has not yet been clarified. Secondly, participants in the current study represent a specific age group, thus the findings should be interpreted with caution without being generalised in other age stages, such as early adolescence. Thirdly, the sample was selected from certain urban regions of the country, specifically the greater Dublin area which should be taken into consideration when making inferences based on these findings. Lastly, the sample size allowed us to perform the specific statistical analyses, however, this was not a nationally representative sample of the general population. Future research should be conducted in order to expand these results in other age groups and in other regions across the country.

\section{Conclusions}

The restricted knowledge around depression, especially when compared with similar cohorts from different cultures (Reavley \& Jorm, 2011; Reavley, McCann, \& Jorm, 2012), coupled with elevated rates of depression and suicide, place Irish youth in critical need for receiving evidence-based interventions designed to increase their knowledge of mental health in general and depression symptoms in particular. The findings of the present study stress the importance of developing new school-based interventions or revising existing ones to increase MHL levels of depression among Irish youth. Although adolescents were capable of recognising the occurrence of a mental health problem, they lacked the ability to identify certain manifestations of depression and therefore perceive the magnitude of the condition. Pupils could benefit from interventions tailored to further raise awareness of specific depression symptoms included among the diagnostic criteria for depressive disorders, but not usually identified, i.e. changes in thoughts, fatigue and low value of self. Linking these symptoms to depression and underlining the vital importance to seek help for addressing them through school-based interventions would contribute towards advancing mental health in Irish adolescents. Furthermore, integrating gender differences in designing school-based interventions could maximize their applicability and address the real needs of the beneficiaries. 


\section{References}

Ajzen, I. (1991). The Theory of planned behaviour. Organisation Behaviour and Human Decision Processes, 50, 179-211.

American Psychiatric Association. (2013). Diagnostic and statistical manual of mental disorders: DSM-5. Washington, D.C: American Psychiatric Association.

Avenevoli, S., Swendsen, J., He, J. P., Burstein, M., \& Merikangas, K. R. (2015). Major depression in the National Comorbidity Survey-Adolescent Supplement: prevalence, correlates, and treatment. Journal of the American Academy of Child \& Adolescent Psychiatry, 54(1), 37-44. http://dx.doi.org/10.1016/j.jaac.2014.10.010

Belfer, M. L. (2007). Critical review of world policies for mental health care for children and adolescents. Current Opinion in Psychiatry, 20, 349. http://dx.doi.org/10.1097/YCO. 0b013e3281bc0cf4

Belfer, M. L., \& Saxena, S. (2006). WHO child atlas project. The Lancet, 367, 551-552. http://dx.doi.org/10.1016/S0140-6736(06)68199-3

Boldero, J. \& Fallon, B. (1995). Adolescent help-seeking: What do they get help for and from whom? Journal of Adolescence, 18, 193-209.

Burns, J. R., \& Rapee, R. M. (2006). Adolescent mental health literacy: Young people's knowledge of depression and help seeking. Journal of Adolescence, 29, 225-239. http://dx.doi.org/10.1016/j.adolescence.2005.05.004

Byrne, S., Swords, L., \& Nixon, E. (2015). Mental health literacy and help-giving responses in irish adolescents. Journal of Adolescent Research, 30, 477. http://dx.doi.org/10.1177/ 0743558415569731

Chambers, D. \& Murphy, F. (2011). Learning to reach out: young people, mental health literacy and the Internet. Dublin: Inspire Ireland Foundation.

Coughlan, H., Tiedt, L., Clarke, M., Kelleher, I., Tabish, J., Molloy, C.. . Cannon, M. (2014). Prevalence of DSM-IV mental disorders, deliberate self-harm and suicidal ideation in early adolescence: An Irish population-based study. Journal of Adolescence, 37(1), 1-9. http://dx.doi.org/10.1016/j.adolescence.2013.10.004

Cotton, S. M., Wright, A., Harris, M. G., Jorm, A. F., \& McGorry, P. D. (2006). Influence of gender on mental health literacy in young Australians. Australian and New Zealand Journal of Psychiatry, 40, 790-796. http://dx.doi.org/10.1080/j.1440-1614.2006.01885.x

De Leo, D., \& Too, L. S. (2014). Suicide and depression. In Okpaku, S. O. (Ed.). Essentials of global mental health. Cambridge University Press.

de Macedo, J. Q., Khanlou, N., \& Luis, M. A. V. (2015). Use of vignettes in qualitative research on drug use: Scoping review and case example from brazil. International Journal of Mental Health and Addiction, 13, 549-562. http://dx.doi.org/10.1007/s11469-015-9543-4 
Department of Education and Skills. (2013). Well-being in Post-Primary Schools. Guidelines for Mental Health Promotion and Suicide Prevention. Department of Education and Skills/Health Service Executive/Department of Health: Ireland Available: https://www.education.ie/en/Publications/EducationReports/Well_Being_PP_Schools_Guidel ines_Summary.pdf

Dolphin, L., \& Hennessy, E. (2014). Adolescents' perceptions of peers with depression: An attributional analysis. Psychiatry Research, 218, 295-302. http://dx.doi.org/10.1016 /j.psychres.2014.04.051

Finch, J. (1987). The vignette technique in survey research. Sociology, 21, 105-114. http://dx.doi.org/10.1177/0038038587021001008

Ganong, L. H., \& Coleman, M. (2006). Multiple segment factorial vignette designs. Journal of Marriage and Family, 68, 455-468. http://dx.doi.org/10.1111/j.1741-3737.2006.00264.x

Gulliver, A., Griffiths, K. M., \& Christensen, H. (2010). Perceived barriers and facilitators to mental health help-seeking in young people: A systematic review. BMC Psychiatry, 10(1), 113-113. http://dx.doi.org/10.1186/1471-244X-10-113

Jorm, A. F., Kelly, C. M., Wright, A., Parslow, R. A., Harris, M. G., \& McGorry, P. D. (2006). Belief in dealing with depression alone: results from community surveys of adolescents and adults. Journal of affective disorders, 96(1), 59-65.

Jorm, A. F., Korten, A. E., Jacomb, P. A., Christensen, H., Rodgers, B., \& Pollitt, P. (1997). Mental health literacy: a survey of the public's ability to recognise mental disorders and their beliefs about the effectiveness of treatment. Medical journal of Australia, 166, 182-186.

Lam, L. T. (2014). Mental health literacy and mental health status in adolescents: A population-based survey. Child and Adolescent Psychiatry and Mental Health, 8(1), 26-26. http://dx.doi.org/10.1186/1753-2000-8-26

Leighton, S. (2009). Adolescents' understanding of mental health problems: conceptual confusion. Journal of Public Mental Health, 8, 4 - 14. http://dx.doi.org/10.1108 /174657292 00900009

Leighton, S. (2010). Using a vignette-based questionnaire to explore adolescents' understanding of mental health issues. Clinical Child Psychology and Psychiatry, 15, 231-250. http://dx.doi.org/10.1177/1359104509340234

Lynch, F., Mills, C., Daly, I., \& Fitzpatrick, C. (2006). Challenging times: Prevalence of psychiatric disorders and suicidal behaviours in irish adolescents. Journal of Adolescence, 29, 555-573. http://dx.doi.org/10.1016/j.adolescence.2005.08.011

Merikangas, K. R., Avenevoli, S., Costello, E. J., Koretz, D., \& Kessler, R. C. (2009). National comorbidity survey replication adolescent supplement (NCS-A): I. Background and measures. Journal of the American Academy of Child \& Adolescent Psychiatry, 48, 367-379. http://dx.doi.org/10.1097/CHI.0b013e31819996f1 
Merikangas, K. R., He, J. P., Burstein, M., Swanson, S. A., Avenevoli, S., Cui, L., ... \& Swendsen, J. (2010). Lifetime prevalence of mental disorders in US adolescents: results from the National Comorbidity Survey Replication-Adolescent Supplement (NCS-A). Journal of the American Academy of Child \& Adolescent Psychiatry, 49, 980-989. http://dx.doi.org/ 10.1016/j.jaac.2010.05.017

Ogden, J. (2012). Health psychology. McGraw-Hill Education (UK).

Reavley, N. J., Cvetkovski, S., Jorm, A. F., \& Lubman, D. I. (2010). Help-seeking for substance use, anxiety and affective disorders among young people: Results from the 2007 australian national survey of mental health and wellbeing. Australian and New Zealand Journal of Psychiatry, 44, 729-735. http://dx.doi.org/10.3109/00048671003705458

Reavley, N. J., \& Jorm, A. F. (2011). Young people's recognition of mental disorders and beliefs about treatment and outcome: Findings from an australian national survey. Australian and New Zealand Journal of Psychiatry, 45, 890-898. http://dx.doi.org/10.3109 /00048674.2011.614215

Reavley, N. J., McCann, T. V., \& Jorm, A. F. (2012). Mental health literacy in higher education students. Early Intervention in Psychiatry, 6(1), 45-52. http://dx.doi.org/ 10.1111/ j.1751-7893.2011.00314.x

Rickwood, D., White, A., \& Eckersley, R. (2007). Overview of current trends in mental health problems for Australia's youth and adolescents. Clinical Psychologist, 11, 72-78. http://dx.doi.org/10.1080/13284200701870970

Sen, B. (2004). Adolescent propensity for depressed mood and help seeking: Race and gender differences. The Journal of Mental Health Policy and Economics, 7, 133.

Vanheusden, K., van der Ende, J., Mulder, C. L., van Lenthe, F. J., Verhulst, F. C., \& Mackenbach, J. P. (2009). Beliefs about mental health problems and help-seeking behavior in dutch young adults. Social Psychiatry and Psychiatric Epidemiology, 44, 239-246. http://dx.doi.org/10.1007/s00127-008-0428-8

Williams, B., \& Pow, J. (2007). Gender differences and mental health: An exploratory study of knowledge and attitudes to mental health among scottish teenagers. Child and Adolescent Mental Health, 12(1), 8-12. http://dx.doi.org/10.1111/j.1475-3588.2006.00413.x

Wright, A., Jorm, A. F., Harris, M. G., \& McGorry, P. D. (2007). What's in a name? is accurate recognition and labelling of mental disorders by young people associated with better help-seeking and treatment preferences? Social Psychiatry and Psychiatric Epidemiology, 42, 244. http://dx.doi.org/10.1007/s00127-006-0156-x

Youssef, N. N., Atienza, K., Langseder, A. L., \& Strauss, R. S. (2008). Chronic abdominal pain and depressive symptoms: analysis of the national longitudinal study of adolescent health. Clinical Gastroenterology And Hepatology: The Official Clinical Practice Journal Of The American Gastroenterological Association, 6, 329-332. http://dx.doi.org/10.1016/ j.cgh.2007.12.019 
Appendix

Appendix 1. Female Character Vignette

Vanessa is in transition year. Last year she was getting on fine, but recently Vanessa has found herself losing interest in things. For example, she used to love films, but she rarely enjoys them anymore. She also finds that she can't get to sleep most nights and she feels less energetic in school. It's harder to stay focused on what the teacher is talking about than it used to be, but if she really tries she can keep up. Once or twice she has pretended to be sick and has not gone into school. She thinks a few of her friends are picking up on it, but so far she has denied it to them. She has skipped the odd training too, but she doesn't like letting the girls down so she still tries to go, but she doesn't care if they win matches. She thinks her mum and dad are worried that she spends more time in her room in the evenings. Sometimes thinking if life is worth living. Some nights she still meets up with friends, but last week they brought this up and she found herself minimising what has being going on and telling them not to worry.

\section{Appendix 2. Male Character Vignette}

Killian is in transition year. Last year he was getting on fine, but recently Killian has found himself losing interest in things. For example, he used to love films, but he rarely enjoys them anymore. He also finds that he can't get to sleep most nights and he feels less energetic in school. It's harder to stay focused on what the teacher is talking about than it used to be, but if he really tries he can keep up. Once or twice he has pretended to be sick and has not gone into school. He thinks a few of his friends are picking up on it, but so far he has denied it to them. He has skipped the odd training too, but he doesn't like letting the lads down so he still tries to go, but he doesn't care if they win matches. He thinks his mum and dad are worried that he spends more time in his room in the evenings. Sometimes thinking if life is worth living. Some nights he still meets up with friends, but last week they brought this up and he found himself minimising what has being going on and telling them not to worry.

\section{Copyright Disclaimer}

Copyright reserved by the author(s).

This article is an open-access article distributed under the terms and conditions of the Creative Commons Attribution license (http://creativecommons.org/licenses/by/3.0/). 